\title{
Assessment of Sustainable Regional Development Policies: A Case Study of Jambi Province, Indonesia
}

\author{
Novita Erlinda \\ Jambi Provincial Agency, Jambi, Indonesia \\ Akhmad Fauzi \\ Bogor Agricultural University, Bogor, Indonesia \\ Slamet Sutomo \\ Institute of Statistics, Jakarta, Indonesia \\ Eka Intan Kumala Putri \\ Bogor Agricultural University, Bogor, Indonesia
}

\begin{abstract}
This paper presents a study of sustainable regional development using multi-criteria analysis. The aim of this paper is to provide an evaluation framework that can be used for the assessment of sustainable regional development using multi criteria linked to development scenarios set by stakeholders. This study was carried out in Jambi Province in Indonesia where balancing sustainable development is constrained by the fact that conservation areas make up the majority of the region. The study employs four alternative policy scenarios for regional sustainable development: (1) business as usual; (2) development based on regional competitiveness; (3) development based on local resources; and (4) regional development based on non-extractive scenario. These four scenarios were assessed using the FLAG Model and the Imprecise Decision Model. Results from analysis show that development policy scenarios based on utilization of local resources and non-extractive economic activities are the most sustainable way of regional development. The study shows the trade-off among policy scenarios must be faced by policy makers in the region either to pursue high economic growth at the cost of the environment or vice versa.
\end{abstract}

Keywords: sustainable regional development, sustainability assessment, FLAG Model, Imprecise Decision Model

\section{Introduction}

Sustainability has been the major concern of development at both the national and regional level. Achieving balanced economic, social, and environmental goals has prompted policy makers to pursue

Novita Erlinda, Dr., Graduate Program of Rural Planing and Development Bogor Agricultural University and Jambi Provincial Agency, Jambi, Indonesia.

Akhmad Fauzi, Ph.D., Prof., Department of Resource and Environmental Economics, Bogor Agricultural University, Bogor, Indonesia.

Slamet Sutomo, Dr., Graduate Program of Rural Planning and Development Bogor Agricultural University and Institute of Statistics, Jakarta, Indonesia.

Eka Intan Kumala Putri, Dr., Department of Resource and Environmental Economics, Bogor Agricultural University, Bogor, Indonesia.

Correspondence concerning this article should be addressed to Akhmad Fauzi, Department of Resource and Environmental Economics, Bogor Agricultural University, Jl. Kamper Wing 10 Level 4 Kampus IPB Darmaga, Bogor 16680, Indonesia. 
measurable and feasible sustainable indicators of sustainable development. In recent years, concern regarding sustainability has also shifted from mostly national and international agendas to more local or regional development (Giaoutzi \& Nijkamp, 1993; Nijkamp \& Vreeker, 2000; Clement, Hansen, \& Bradley, 2003; Patterson \& Theobold, 1995). Nijkamp and Vreeker (2000) argued that the shift to a more regional development notion of sustainability is due to the fact that the region is properly demarcated: therefore, an empirical or operational measure of sustainability could be performed. In addition, in a region, control and administrative competence are usually regulated, making it more relevant to assess the sustainability of the policy delivered in the region.

Concern about integrating sustainable development into regional development has raised a new notion: Sustainable Regional Development or SRD. Therefore, SRD is the concept of development that integrates sustainable development principles into regional development practice (Clement et al., 2003). Clement et al. (2003) stated that SRD encompasses all activities and instruments that promote sustainable development within regional economic activities. The integration of sustainable development into regional development is arguably important for regional development as a whole. Schleicher-Tappeser and Lukesch (1999), for example, argued that regional development is not a singular concept. While regional development works at the spatial level, it needs qualitative assessment that can be filled with sustainable development concepts. Therefore, in essence, SRD encompasses both integrative concepts and integrative devices (Haughton \& Councel, 2004).

Despite the fact that decades have passed since the sustainability concept was raised in international agendas, the measurement and implementation of sustainable indicators are still challenging issues, especially in the regional development context (Gibson, 2006). Even though progress has been made in the science of sustainability assessment, the challenge remains in finding the appropriate match between theory and its implementation (Poveda \& Lipsett, 2011). Poveda and Lipsett (2011) further argued that the assessment and measurement of sustainability are two concepts that go hand-in-hand. Nevertheless, assessment is much more complex since it involves the participation of stakeholders and it should be meaningful in terms of policy analysis or the decision making process. This notion of sustainability assessment is shared by regional development whereby not only does it have to be beneficial to the region (meaningful), but also it has to involve the active participation of stakeholders.

In the context of Indonesia, especially in regional development, assessing sustainability is both timely and important. Sustainable development is not only important in a moral sense, but it is also mandated in the long-term national development plan as stated in Law 17/2007. It is worth noting that, as reported by The World Bank in 2009, Indonesia's development path during the last decades has cost environmental degradation ranging from $0.13 \%$ to $7 \%$ of the gross domestic product (GDP). Therefore, adopting a sustainable paradigm is not only urgently required to reverse environmental degradation, but it also could save Indonesia's financial resources (Fauzi \& Oxtavianus, 2014).

Such a situation is faced by decision makers in Jambi Province, Indonesia. As shown in Figure 1, Jambi lies in the middle part of Sumatera Island. It is bordered by Riau Province to the north, West Sumatra, and Bengkulu Provinces to the west, South Sumatra Province to the south, and the South China Sea and Bangka Belitung Province to the east. Geographically, Jambi has a strategic position since it has close and direct access to Malacca and Singapore via the Strait of Malacca.

Home to more than three million people, much of the 53.4 thousand $\mathrm{km}^{2}$ of the Jambi area (Jambi Provincial Planning Agency, 2014) is occupied by conservation areas, which are critical in supplying various 
environmental services such as clean water in the Jambi region and its neighbouring regions. Jambi has four conservation areas classified as Nasional Parks (IUCN): (1) Kerinci Seblat, (2) Berbak, (3) Bukit Tiga Puluh, and (4) Bukit Dua Belas Nasional Park. The total area of these National Parks is 669.130 hectares or approximately $13 \%$ of the region's land area. These national parks, based on Government Regulation Number $26 / 2008$, are designated as national strategic areas. In Jambi's case, the designation of the four national parks as national strategic areas is based on their function to support the environmental carrying capacity for both the province and other neighbouring provinces. The designation of the Jambi national parks as national strategic areas is also due to Jambi's rich biodiversity of flora and fauna. Some endangered species such as the Sumatran tiger and the Sumatran rhinoceros are found in Jambi's conservation areas. The province is also a waterway of the island's longest river: Batanghari River.

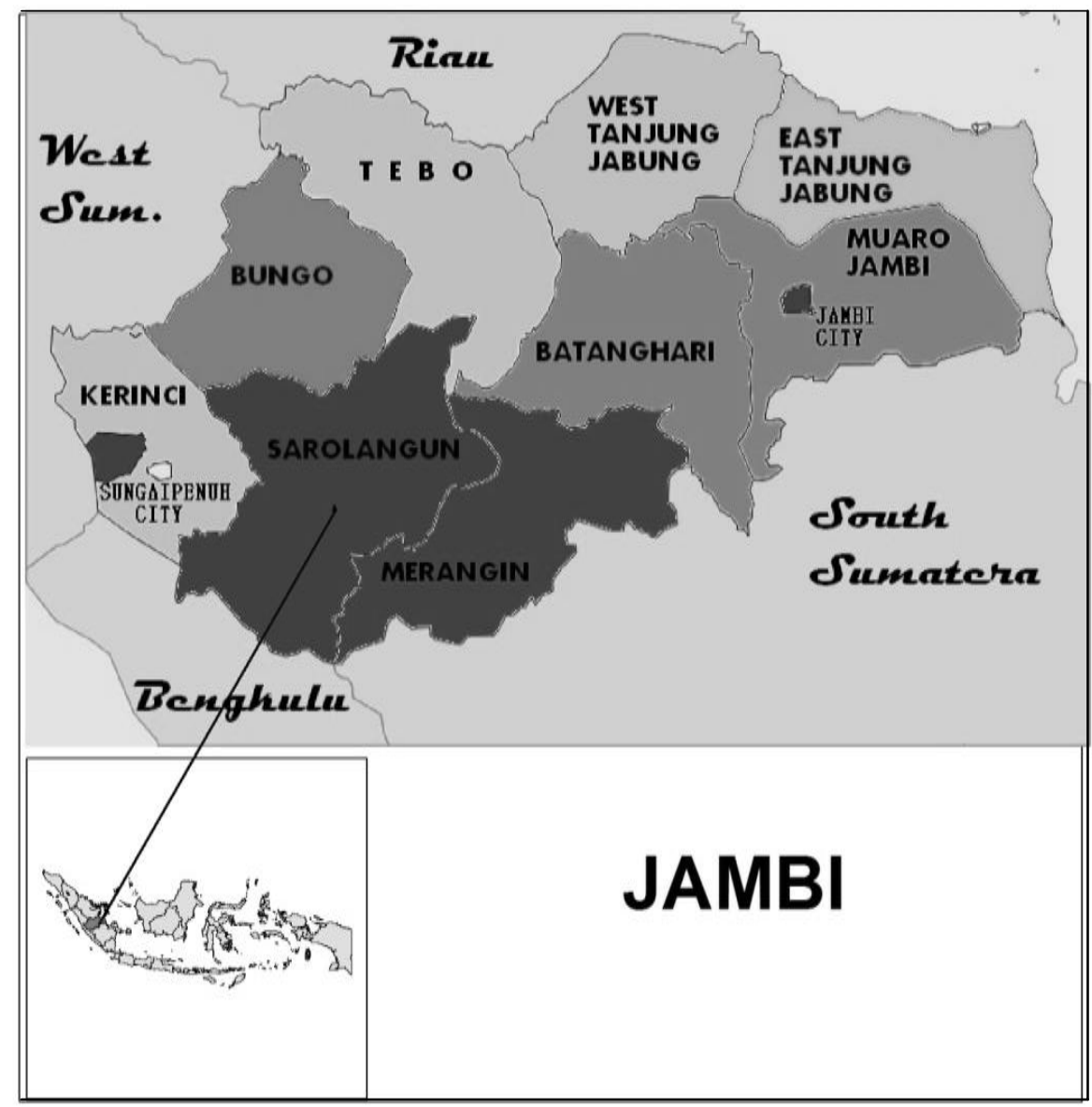

Figure 1. Map of Jambi Province.

Even though Jambi's economic development is constrained by the spatial distribution of settlement and conservation areas, the provincial government of Jambi has set an ambitious target of economic development aiming at an $8 \%$ growth rate per year. Such a high target of economic growth might not be feasible to achieve, but also comes at the cost of environmental degradation, especially if the local government is also aiming at the conservation areas as a target for economic growth.

During the last five years, the local government of Jambi has set out a development paradigm, which emphasizes the economic pillar of sustainable development: Jambi EMAS. The name "Jambi EMAS" literally 
means "Jambi Gold," and it is an acronym for economic prosperity and social welfare. As implied by such a development jargon, nothing in this paradigm contains the environmental aspect of sustainability. Jambi EMAS expired at the end of 2015, and the new provincial administration will take place from March 2016 onward. Therefore, it is important to not only evaluate the current (existing) development paradigm, but also to set out several alternative development agendas that are suitable for Jambi Province by taking into account several constraints of achieving the development targets. In this context, the sustainability regional development assessment approach is deemed suitable for regional development in Jambi Province. It is the objective of this paper to address such an assessment.

\section{Methods}

This study was developed based on a multi-criteria analysis (MCA) by means of FLAG approach of sustainability assessment (Nijkamp \& Ouwersloot, 1996; Hermanides \& Nijkamp, 1998; Lancker \& Nijkamp, 2000; Leeuwen, Vreeker, \& Rodenburg, 2003). The FLAG approach is basically a multi-criteria analysis to assess whether one or more policy alternatives can be classified as acceptable or not acceptable given a set of criteria. The method is carried out by comparing the impact value with a set of reference values known as critical threshold values or CTVs. The CTVs set the maximum and the minimum tolerable boundary of the acceptable indicators. FLAG, as its name indicates, uses a colour-coded indicator to indicate a development alternative poses risk or is acceptable. The colour-coded indicator is presented using bands of green (Section 1), yellow (Section 2), red (Section 3), and black (Section 4) colour as shown in Figure 2.

\begin{tabular}{|llllll|}
\hline & CTVmin & & CTV & & CTVmax \\
\hline & & & & & \\
& & & & \\
& & & & & Stop \\
& No concern & Risk detected & 100 & High risk & Section 4 \\
\hline
\end{tabular}

Figure 2. FLAG band with indicator.

As can be seen from Figure 2, the green flag indicates that no concern is raised for the decision maker regarding pursuing sustainable development while the yellow flag indicates that risks have been detected. The red and black bands indicate that the development is no longer sustainable and some reverse trend or termination should be executed.

The determination of sustainability is calculated by the following formulas:

$$
\begin{aligned}
& S(x)=(C T V-x) /(C T V \min -C T V) \text { for } x<C T V \\
& S(x)=(x-C T V) /(C T V \max -C T V) \text { for } x>C T V
\end{aligned}
$$

The formulas basically state that when the indicator is below the critical threshold value $(x<\mathrm{CTV})$, the sustainability of the indicator $S(x)$ is calculated by the difference between the CTV and the value of the indicator divided by the difference between the minimum CTV and the CTV. For the value above the CTV, the calculation is reversed and the divisor is the difference between the maximum CTV and the CTV.

The second step of analysis in this study uses the Imprecise Decision Model (IDM) to accommodate the nature of the uncertainties and risks associated with policy alternatives. The reason for choosing this type of approach arises from the fact that the nature of information available to decision makers is largely vague and 
imprecise. The vagueness and imprecision of the information might arise from the lack of systematic data or from the dynamic of the policy targets set out by the policy makers, as well as inconsistencies and complexities in making decisions for a long-term framework. Such a situation is most likely to occur in developing countries, which makes it difficult to get the best data. Furthermore, the lack of human resource capacity makes it difficult to obtain reliable information.

The analysis of the Imprecise Decision Model was carried out by the DecideIT software developed by Danielson, Ekenberg, Johansson, and Larsson (2003). It is based on expected value theory, sometimes expressed in monetary value by equation (3):

$$
E V\left(A_{i}\right)=\sum_{k=1}^{s} w_{k}\left(\sum_{J=1}^{m} P_{i j} V_{i j}\right)
$$

where $w_{k}$ is the weighted parameter of the $k^{\text {th }}$ criteria. The variable $V_{i j}$ represents the value of the $i^{\text {th }}$ indicator and $j^{\text {th }}$ alternative, while $p_{i j}$ represents the probability of the $i^{\text {th }}$ indicator and $j^{\text {th }}$ alternative, respectively. As stated previously, the IDM is based on the MCA value measurement model whereby the best alternative is chosen by the Delta Method. The Delta Method is written as:

$$
\delta_{i j}=E V\left(A_{i}\right)-E V\left(A_{j}\right)
$$

which is simply the difference between the expected value of two alternatives. Once the Delta value was obtained, the DecideIT decision tool evaluates the relative strength among the alternatives to assess the best alternative. The relative strength of these alternatives is denoted by:

$$
\begin{aligned}
\operatorname{rel}\left(\delta_{i j}\right) & =\left[\max \left(\delta_{i j}\right)+\min \left(\delta_{i j}\right)\right] / 2 \\
& =\left[\max \left(\delta_{i j}\right)-\max \left(\delta_{j i}\right)\right] / 2
\end{aligned}
$$

From those formulations, DecideIT will determine the best alternative based on the expected value derived from the model. In addition to providing the differences among alternatives, DecideIT also provides several decision aids that can be useful for decision-making. The followings are the risk profile and the security threshold.

The risk profile is defined by:

$$
\pi_{\max }=\sum_{X_{i} \leq X} P^{E \max }\left(x_{i}\right)
$$

where $p$ is the probability and $E U$ is the expected value of outcome $X_{i}$. The security threshold is defined as:

$$
S\left(A_{i}, r s\right)=\sum_{V_{i j} \leq r} P_{i j} \leq s
$$

where $S$ is the threshold value and $s$ is the maximum probability of obtaining $r$ or less (Idefeldt \& Danielson, 2006; Idefeldt, 2007). The total ranking of the alternative chosen by the model is calculated based on the formula in equation (9):

$$
\mathcal{L}_{i}=E U\left(A_{i}\right)-\frac{\sum_{j=1}^{n} E U\left(A_{j}\right)}{n}
$$

Even though the IDM is quite popular in business and finance (Danielson et al., 2003; Idefeldt, 2007), few applications related to sustainable development assessment have been studied. Some of these include Mihai, 
Marincea, and Ekenberg (2015) on choosing the sustainable mining policy in Romania and Kivunike, Ekenberg, Danielson, and Tusubira (2015) on sustainable health care provision in Uganda. This study, therefore, is the first one to implement the IDM technique in the context of sustainable regional development.

To implement the model in the regional development planning of Jambi Province, four alternatives of development scenarios along with economic, social, and environment indicators were developed. The four alternatives were: (1) business as Usual or BAU (Alternative 1); (2) increased local competitiveness, known as PDS (Alternative 2); (3) the use of local resources or MSDL (Alternative 3); and (4) development based on non-extractive activities, known as ENE (Alternative 4). The selection of these alternatives and their associated criteria were based on agreement from a multi-stakeholder focus group discussion attended by representatives of the government, NGOs, universities, communities, and private sectors.

Table 1 presents indicators and the meassurement units for the purpose of the study.

Table 1

Units of Measurement of the Indicators

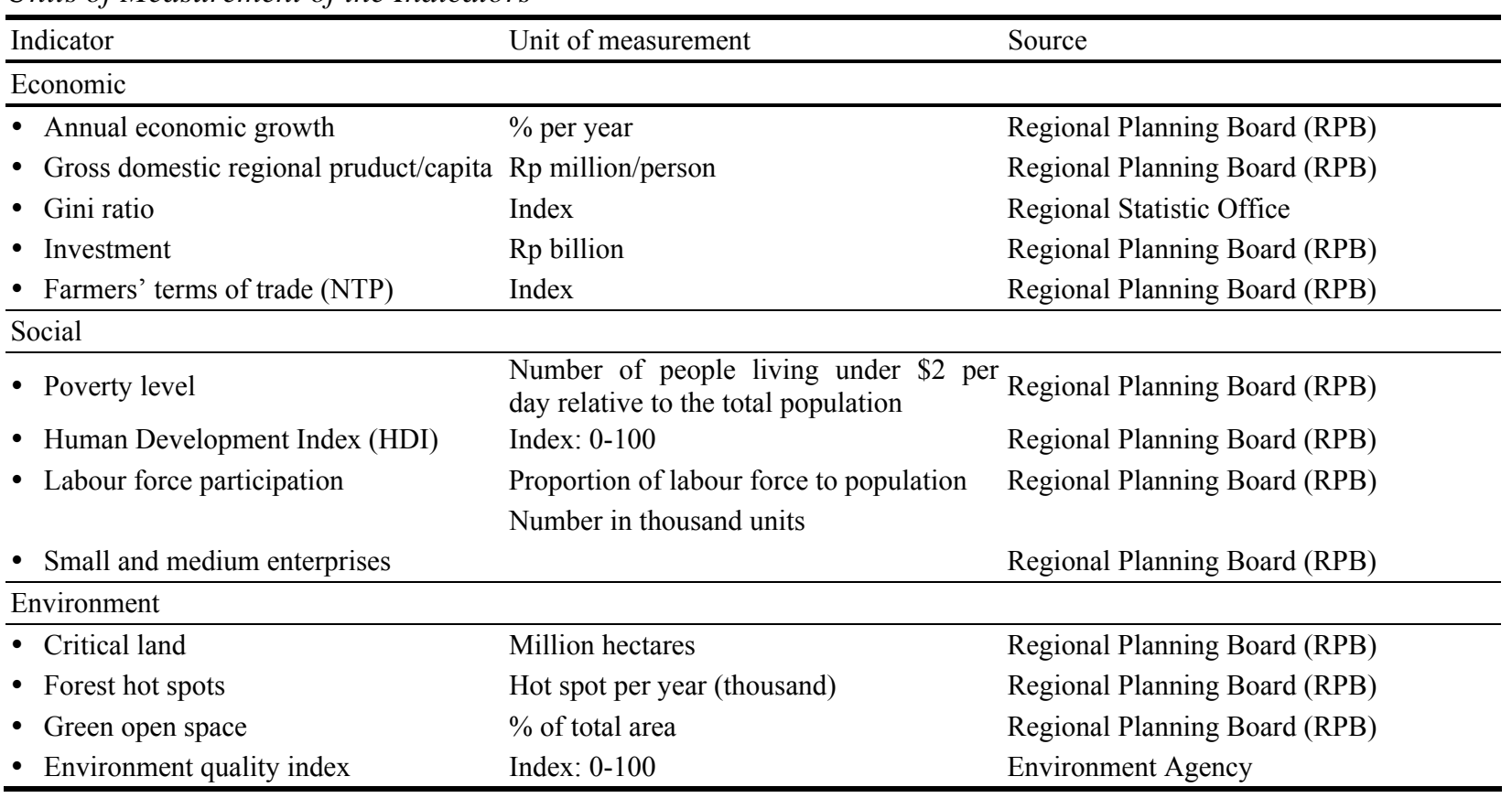

As can be seen from Table 1, each indicator has a different unit of measurement. In order for the IDM to be operational, these measurements have to be normalized using the normalisation technique attained by the formula:

$$
r_{i j}=\frac{a_{i j}}{\sqrt{\sum a_{i j}^{2}}}
$$

where $a_{i j}$ is the unit of indicator of criteria $i$ with alternative $j$. Once the units have been normalized, the comparison among alternatives can be carried out using the index number for 0 to 1 .

As described previously, the study also uses the FLAG model to diagnose the state of sustainability. The FLAG analysis requires critical threshold values (CTVs) for both minimum and maximum values as well as its actual critical values. Table 2 presents the CTVs for the analysis. Each CTV has either good or bad indicators. Good indicators mean that the higher the measurement, the better for those indicators, while bad indicators are the opposite. 
Table 2

CTV Values for FLAG Analysis

\begin{tabular}{lllll}
\hline Indicator & Type & CTVmin & CTV & CTVmax \\
\hline Economics & & & & 9 \\
\hline 1. Economic growth & $\mathrm{G}$ & 4 & 7.8 & 10 \\
2. Income per capita & $\mathrm{G}$ & 3 & 6 & 0.5 \\
3. Gini ratio & $\mathrm{B}$ & 0.25 & 0.34 & 40 \\
4. Investment & $\mathrm{G}$ & 10 & 27 & 100 \\
5. Farmers' terms of trade (NTP) & $\mathrm{G}$ & 80 & 90 & 20 \\
\hline Social & & & 8 & 80 \\
\hline 1. Poverty rate & $\mathrm{B}$ & 5 & 63 & 90 \\
2. The participation labour force & $\mathrm{G}$ & 60 & 81 & 100 \\
3. Small Industry & $\mathrm{G}$ & 50 & 74 & 1.6 \\
4. Human development index (HDI) & $\mathrm{G}$ & 60 & & 1,500 \\
\hline Environment & & & 1.4 & 40 \\
1. Critical land & $\mathrm{B}$ & 0.5 & 30 & 100 \\
2. Hot spot & $\mathrm{G}$ & 500 & 63 & \\
3. Green open space & $\mathrm{G}$ & 20 & 60 & \\
4. Environment index & $\mathrm{G}$ & & & \\
\hline
\end{tabular}

Notes. $\mathrm{G}=$ good indictors, $\mathrm{B}=$ bad indicators.

\section{Results and Discussions}

Table 3 presents the FLAG results. As can be seen from the table, a development policy using business as usual raises more yellow flags (7), red flags (2), a green flag (1), and black flags (3). The business as usual (BAU) scenario yields no green flag on social and environmental dimensions. If the development policy shifts from business as usual, the number of green flags will increase. The number of green flags will be the highest with a scenario of the non-extractive development alternative (5) followed by the local resources scenario (Alternative 3) with three green flags and increased competitiveness with two green flags. Table 3 also presents the distribution of the flags for each dimension. For example, the yellow flag is for the BAU scenario, while the rest are distributed equally between economic and social indicators. Meanwhile, regarding the green flag of the non-extractive scenario, $60 \%$ is attributed to environmental indicators, and $40 \%$ is attributed to economic indicators.

Table 3

Results of the FLAG Model for Four Policy Alternatives

\begin{tabular}{|c|c|c|c|c|c|c|c|c|c|c|c|c|c|c|c|c|}
\hline \multirow[t]{2}{*}{ Policy alternative } & \multicolumn{4}{|c|}{ Total flags } & \multicolumn{4}{|c|}{ Economics } & \multicolumn{4}{|c|}{ Social } & \multicolumn{4}{|c|}{ Environment } \\
\hline & G & $\mathrm{Y}$ & $\mathrm{R}$ & B & G & $\mathrm{Y}$ & $\mathrm{R}$ & B & $\mathrm{G}$ & $\mathrm{Y}$ & $\mathrm{R}$ & $\mathrm{B}$ & $\mathrm{G}$ & $\mathrm{Y}$ & $\mathrm{R}$ & $\mathrm{B}$ \\
\hline Business as usual (BAU) & 1 & 7 & 2 & 3 & 1 & 3 & 0 & 1 & 0 & 2 & 0 & 2 & 0 & 2 & 2 & 0 \\
\hline Competitiveness (PDS) & 2 & 4 & 3 & 4 & 2 & 2 & 1 & 0 & 0 & 2 & 0 & 2 & 0 & 0 & 2 & 2 \\
\hline Local resources (MSDL) & 3 & 6 & 3 & 1 & 1 & 3 & 1 & 0 & 1 & 1 & 1 & 1 & 1 & 2 & 1 & 1 \\
\hline Non-extractive (ENE) & 5 & 5 & 2 & 1 & 2 & 2 & 1 & 0 & 0 & 2 & 1 & 1 & 3 & 1 & 0 & 0 \\
\hline
\end{tabular}

Having analysed the policy scenarios in terms of the occurrence of flags, the next discussion presents the results from the IDM. The results from the IDM are a further refinement of the FLAG model. In addition, by using the IDM, one can compare policy alternatives and perform risk analysis. The IDM also presents both ordinal and cardinal ranking among alternatives. 


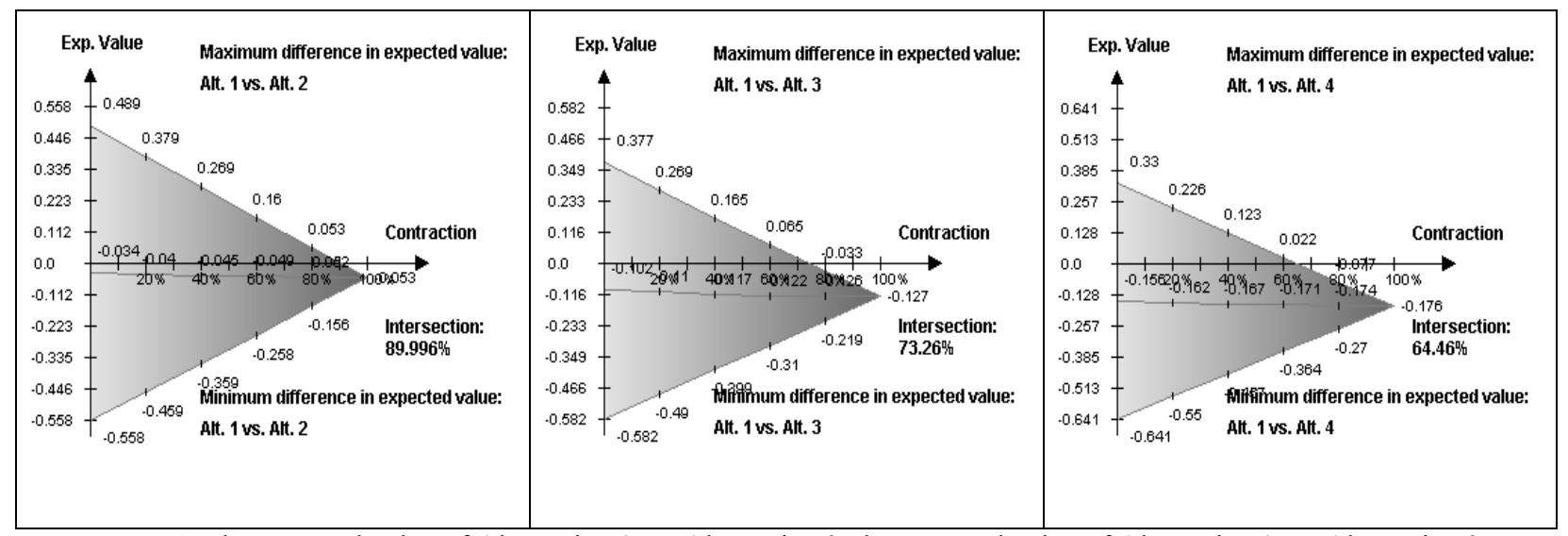

Figure 3. The expected value of Alternative 1 vs. Alternative 2, the expected value of Alternative 1 vs. Alternative 3, and the expected value of Alternative 1 vs. Alternative 4.

Figure 3 depicts the comparison of Alternative 1 with the other alternatives in turn (i.e., Alternative 2, Alternative 3, and Alternative 4). As can be seen from Figure 3, the larger the area, the better the alternative compared with the other alternatives. For example, when comparing Alternative 1 (BAU) and Alternative 2 (competitiveness), the shaded triangle area of Alternative 2 is larger than the shaded area of Alternative 1. This means that Alternative 2 is preferred over Alternative 1 (BAU). Similarly, when comparing Alternative 3 to Alternative 1, the area of Alternative 3 is larger than Alternative 1, which indicates that Alternative 3 (local resources) is more preferable than Alternative 1 (BAU). Comparing Alternative 4 with Alternative 1, the figure also indicates that Alternative 4 is more preferable than Alternative 1.

Figure 3 provides comparison in terms of the maximum and minimum differences between two alternatives. For example, when comparing Alternative 1 (BAU) and Alternative 2 (PDS), if the best things happen, the difference is positive 0.489 of a point, while if the worst things occur, the difference is negative -0.558 . Those numbers correspond to the normalized units of the criteria being used as described in Table 1 .

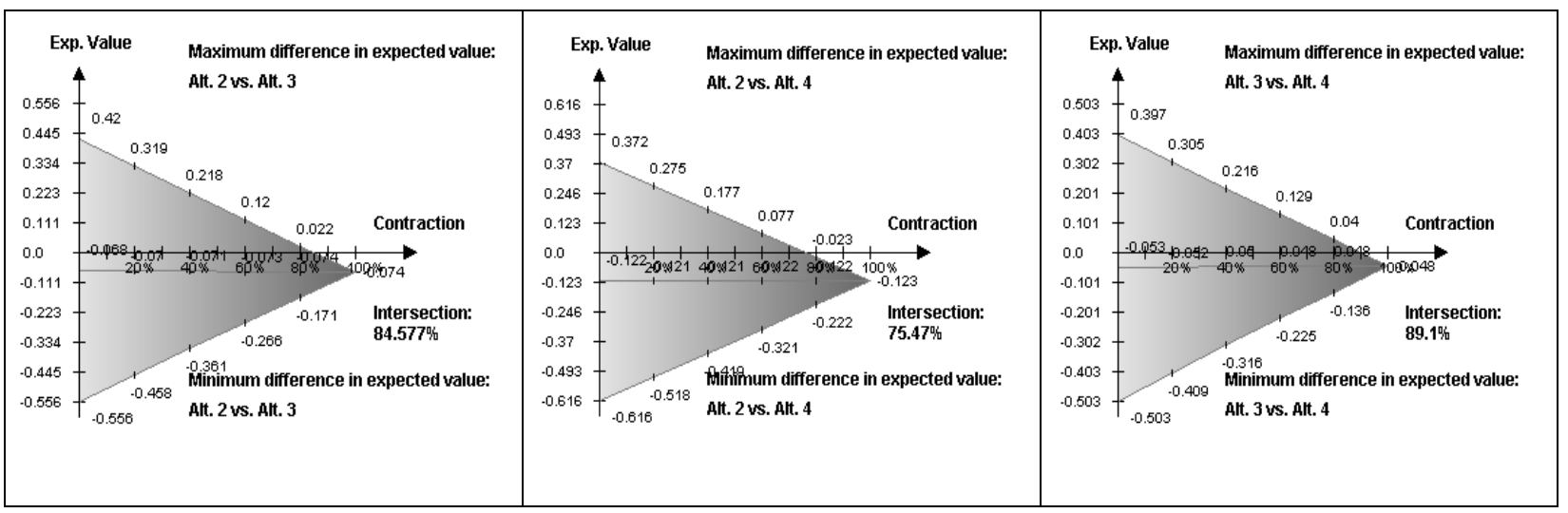

Figure 4. The expected value of Alternative 2 vs. Alternative 3, the expected value of Alternative 2 vs. Alternative 4 , and the expected value of Alternative 3 vs. Alternative 4.

Figure 4 presents a comparison of Alternative 2 versus Alternative 3 and Alternative 4 . As can be seen in Figure 4, Alternative 3 is preferred to Alternative 2. Similarly, Alternative 4 is also better compared with Alternative 2 as shown in the larger shaded area. Figure 4 also indicates that Alternative 4 (ENE) is better than Alternative 3, as the area of Alternative 4 is bigger than Alternative 3. 
Figure 5 shows the cardinal ranking for the four alternatives with contraction levels of $0 \%$, $70 \%$, and $100 \%$. The contraction level represents the degree of belief regarding imprecise information. For example, when the contraction level is $0 \%$, it is believed that the data lie in the range of its minimum and maximum value, while at the contraction level of $100 \%$, it is believed that the data are close to its actual value. As can be seen from Figure 5, Alternative 4 dominated other alternatives while Alternative 1 (i.e., business as usual) is the less preferable alternative among four scenarios of regional development.

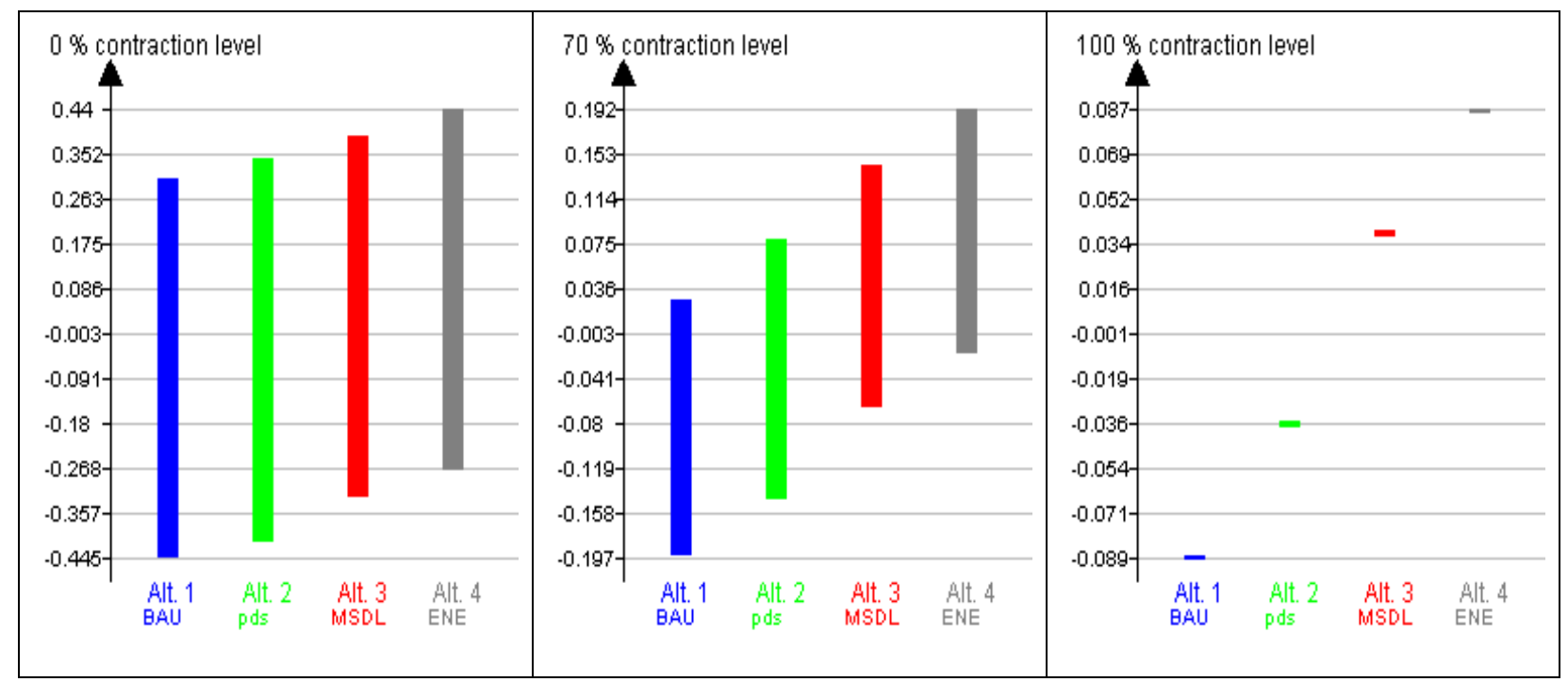

Figure 5. Cardinal ranking contraction levels of $0 \%, 70 \%$, and $100 \%$.

As in any modelling scenario, the model is relatively sensitive to any uncertainties resulting from target setting by the decision makers. To address such an issue, a sensitivity analysis using the tornado diagram was carried out. The tornado diagram represents variables and criteria that show a greater impact on the expected value of alternatives. The result of the tornado analysis is presented in Figure 6.

As can be seen from the tornado diagram (Figure 6), the left part (red colour) indicates that the expected values are influenced in a negative way while the right part (green bar) shows they are influenced in a positive way. For example, while Criteria E5 (the economic indicator for Alternative 2) influenced the outcome in a positive way to 0.051 , it also influenced the outcome in a negative way at -0.021 point.

As stated earlier in the method section, one of the advantages of using the IDM is the ability to assess the risk associated with each policy alternative. In the IDM, such a risk can be handled by setting the security threshold. Security thresholds describe an evaluation among information by setting a minimum level of target with certain probability. Figure 7 describes the result of the security threshold assessment by setting the minimum value of 0.2 with the probabilities of $10 \%, 25 \%$, and $50 \%$.

As can be seen from Figure 7, Alternatives 3 and 4 fit into a specific risk profile while Alternative 1 is at risk to be selected at the contraction level up to $70 \%$. Alternative 2 is also at risk, even if it fulfils the thresholds at a lower contraction level.

The partial assessment of the models presents the relationship among alternatives by means of total ranking at the indifferent interval of 5\%. The indifferent interval represents how large the difference of the expected value at a given contraction level needs to be considered different in order for the alternative. 


\begin{tabular}{|c|c|}
\hline Node & Probability Tornado \\
\hline E5: & $-0.021 \square$ \\
\hline E8: & -0.034 \\
\hline E1: & -0.017 \\
\hline C14: & $\begin{array}{ll}-0.027 \square & 0.014\end{array}$ \\
\hline C16: & $-0.016 \square 0.018$ \\
\hline E3: & 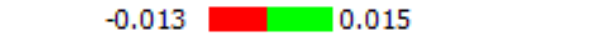 \\
\hline C13: & $\begin{array}{ll}-0.007 & \square \\
\square & 0.014\end{array}$ \\
\hline C15: & $-0.007 \square \quad 0.014$ \\
\hline C19: & $\begin{array}{l}-0.013 \square 0.007 \\
\square \quad 0.07\end{array}$ \\
\hline E4: & 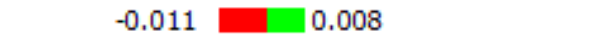 \\
\hline C5: & $-0.012 \square 0.006$ \\
\hline C18: & 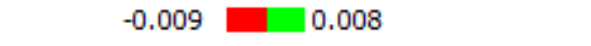 \\
\hline C1: & $-0.011 \square 0.006$ \\
\hline C17: & $-0.008 \square 0.008$ \\
\hline E9: & $-0.01 \square 0.005$ \\
\hline E7: & $0.0 \square 0.015$ \\
\hline C26: & $-0.005 \square-0.009$ \\
\hline C27: & $-0.009 \square 0.005$ \\
\hline $\mathrm{C} 2:$ & $-0.005 \square 0.009$ \\
\hline C7: & $-0.006 \square-0.008$ \\
\hline C36: & 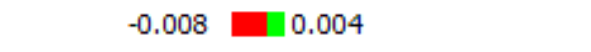 \\
\hline C20: & $-0.003 \square 0.007$ \\
\hline C21: & $-0.003 \square 0.007$ \\
\hline C9: & $-0.006 \square 0.004$ \\
\hline E13: & $-0.006 \square 0.003$ \\
\hline C4: & $-0.003 \square 0.006$ \\
\hline C6: & $-0.003 \square 0.006$ \\
\hline E15: & $-0.003 \square 0.005$ \\
\hline E12: & $-0.003 \square 0.005$ \\
\hline C34: & $-0.003 \square 0.004$ \\
\hline E11: & $-0.002 \square 0.005$ \\
\hline C28: & $-0.002 \square 0.004$ \\
\hline C29: & $-0.003 \square 0.002$ \\
\hline C35: & $-0.002 \square 0.003$ \\
\hline C8: & $-0.002 \square 0.002$ \\
\hline C22: & $-0.002 \square 0.001$ \\
\hline C3: & $-0.001 \mid[0.002$ \\
\hline C23: & $-0.001 \| 0.001$ \\
\hline C24: & $-0.001 \| 0.001$ \\
\hline C30: & $-0.001 \quad \mid 0.0$ \\
\hline E16: & $0.0 \mid 0.001$ \\
\hline
\end{tabular}

Figure 6. Tornado diagram. 


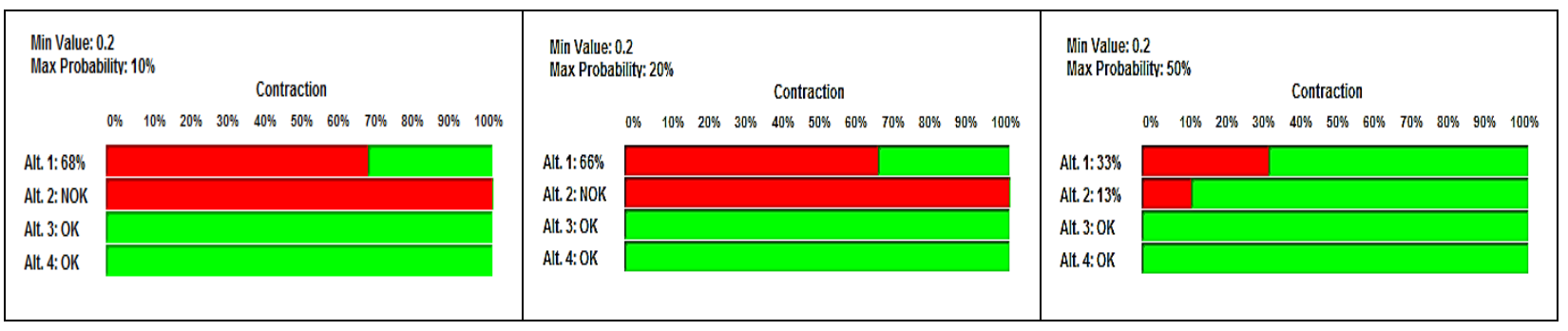

Figure 7. Security threshold assessment with the probabilities of $10 \%, 20 \%$, and $50 \%$.

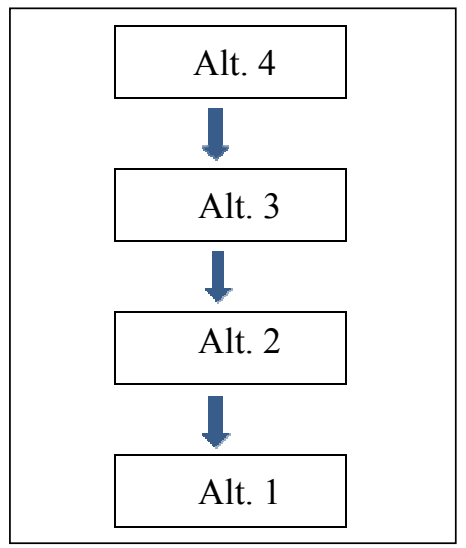

Figure 8. Indifference interval 5\%.

As can be seen from Figure 8, Alternative 4 is better than Alternative 3, and both dominating Alternative 2 and Alternative 1.

\section{Policy Implications}

Having completed both the FLAG and IDM analysis, it can be inferred that the current existing development policy set out by the provincial government, which is aiming for higher economic growth, might not be sustainable in the sense that it might raise social and environmental costs. Achieving development targets using the existing policy will overpass the maximum critical threshold values that can be tolerated by current social and economic thresholds in Jambi Province.

The study indicates that a mix of development scenarios (i.e., combining the promotion of local resources and exploring the non-extractive use of its natural resources) would be more sustainable in the future. This could also prove to be the competitive advantage of the region since the province has a large area of forest conservation area, which could be a double-edge sword of development. If the province uses the business as usual policy, the extensive use of forest products and exploitation of non-renewable resources such as coal, might lead to environmental degradation. For example, the province has recently experienced a massive forest fire resulting in a thick haze for a long period of time. This environmental hazard has caused massive economic downturn in the province and its neighbouring province. It paralyzed economic activities and posed health problems for the people of Jambi Province and other provinces in Indonesia.

In order to implement the development policy based on non-extractive use and local resources, the province has a strong legal backing from Law 23/2009 on environmental protection and management. The law states that the province could use a market-based instrument such as payment for environmental services (PES) and other market mechanisms to develop its huge potential of ecotourism. The province could use the water 
PES scheme with other neighbouring provinces or between districts with the provinces, as it has a huge potential for the water catchment area in the forested area.

Another policy agenda that can be used to implement Alternatives 3 and 4 is that the province could use the green economy framework based on a biodiversity-based economy and low carbon economy. That is, the province could engage in developing its biodiversity potential to support the pharmacy industry, eco-tourism, or agriculture. The low carbon economy could be developed by developing energy alternatives using its water potential or biomass energy from its forest resources. Overall, developing policy development agendas using Alternatives 3 and 4 would be more beneficial for the province in the future. The adoption of such a policy might be both timely and urgent in the next five years since the province has to set up a new development agenda because the current existing Jambi EMAS expired at the end of 2015.

Several policy implications can be drawn from this study. First, by using the IDM, policy makers will be able to assess the risk association with the policy options being chosen. In addition, the IDM will provide a policy platform, which will most likely provide a better outcome for regional economic development. In this study, a policy option based on the non-extractive use of natural resources and using local resources more efficiently would provide a more sustainable development outcome for regional development in Jambi. The non-extractive use of natural resources is part of the so-called Green Economy paradigm. Several programs can be derived from this non-extractive use such as developing eco-tourism, encouraging creative economy, and encouraging the use of ecosystem services. An economic instrument such as payment for environmental services (PES) can be used to encourage the economic exchange of ecosystem services such as water services, carbon trade, or tourism. The provincial government might encourage district level governments (Kabupaten/Kota) to engage in a PES scheme such as the use of water resources between the upstream area of Kerinci Seblat and downstream areas. In order for this scheme to be operational, a bylaw or regional regulation (known as PERDA) needs to be issued by the provincial government.

Second, the study also indicates that encouraging local resources would be the second best option for regional development. Therefore, the regional economy can be boosted by encouraging more small and medium enterprises to participate actively in the economy. Such an involvement of small and medium enterprises needs to be supported by the financial sectors and should be directed toward the nature-based economy and non-extractive activities such as eco-tourism, cultural festivals, and other supporting activities that encourage the use of local resources.

Third, this study also provides a regional development platform using the policy options offered from this study. Since there are risks involved in pursuing high economic growth agendas, the regional government should follow its spatial planning and not adjust very often to accommodate economic expansions. The spatial planning should be used as a benchmark toward pursuing a green economy while at the same time protecting the province's natural resources and its ecosystem services, which are vital for economic development itself.

\section{Concluding Remarks}

The assessment of sustainability for regional development is both timely and important to ensure that the development is not only pursuing economic indicators but is also fulfilling social and environmental criteria. Given the complexity of assessing and measuring sustainability, using a novel approach such as the FLAG and IDM approaches would provide an insight for the local government regarding the state of the sustainability of its development agendas in a simple yet meaningful way. In the context of regional development in the area 
being studied, the findings from this analysis will help provide the local government with a set of different development alternatives, which could be used by policy makers to assess regional development goals. These findings could also be used as lessons learned for other regions in the country or at the national level. Given the lack of the coherent measurement of sustainability in Indonesia, the model being developed in this study could be used as a benchmark for sustainability assessment in the country. Such a proposal is important due to the fact that the lack of awareness in sustainability, especially regional-wise, could create an enormous loss of economic development in Indonesia. Such a cost represents the economic loss that could be used for other purposes of economic development.

Achieving sustainable development, which includes social, economic, and environment criteria, is indeed a challenging issue. In the context of a developing country, such an issue is often exacerbated by a lack of resources and information to address complex issues associated with pursuing the goal of sustainable development. This paper has shown that with the aid of a proper tool and a multi-stake holder dialogue, scenarios of sustainable development can be assessed. In addition, the risk and uncertainties associated with the benefits and costs of development are taken into account. This study also shows that even though the case study is at the level of the provincial government, lessons learned can be drawn and applied to other regional development contexts in both developed and developing countries. A key factor derived from this model is that determining alternative development scenarios along with their relevant indicators plays a key role in developing measurable and achievable development goals. This study also finds that ambitious target setting by decision makers should be matched against alternative development scenarios so that such a target can be evaluated and the policy maker would have a broad view of pursuing development agendas.

\section{References}

Clement, K., Hansen, M., \& Bradley, K. (2003). Sustainable regional development: Learning from Nordic experience. Nordregio Report, Stockholm.

Danielson, M., Ekenberg, L., Johansson, J., \& Larsson, M. (2003). The DecideIT decision tool. Proceedings of ISIPTA’03, J. M. Bernard, T. Seidenfelf, and M. Zaffalon (Eds.), Carleton Scientific, 204-217.

Fauzi, A., \& Oxtavianus, A. (2014). The measurement of sustainable development in Indonesia. Jurnal Ekonomi Pembangunan, 15(1), 68-83.

Giaoutzi, M., \& Nijkamp, P. (1993). Decision support model for regional sustainable development. UK: Avebury.

Gibson, R. B. (2006). Sustainability assessment: Basic components of a proctical approach. Impact Assessment Project Appraisal, 24, 170-182.

Haughton, G., \& Councel, D. (2004). Regions and sustainable development: Regional planning matters. The Geography Journal, $170(2), 135-145$.

Hermanides, G., \& Nijkamp, P. (1998). Multi criteria evaluation of sustainable agriculture land use: A case study of lesvos. Multi Criteria Analysis for Land Use Management. In E. Beinat and P. Nijkamp (Eds.), Kluwer, Dondrecht, 61-78.

Idefeldt, J., \& Danieson, M. (2006). Multi-criteria decision analysis software for uncertain and imprecise information. Proceedings of the 11th Annual Conference of Asia Pacific Decision Sciences Institute, Hong Kong, June 14-18, 589-598.

Idefeldt, J. (2007). An applied approach to numerically imprecise decision making (Dissertation Thesis, Sweden University) (In Swedish).

Jambi Provincial Planning Agency. (2014). Jambi Dalam Angka (Jambi in numbers). The Provincial Goverment of Jaambi, Indonesia.

Kivunike, F. N., Ekenberg, L., Danielson, M., \& Tusubira, F. (2015). Using a structured approach to evaluate ICT4D: Healthcare delivery in Uganda. The Electronic Journal of Information Systems in Developing Countries, 66(8), 1-16.

Lancker, E., \& Nijkamp, P. (2000). A policy scenario analysis of sustainable agricultural development options: A case study for Nepal. Impact Assessment and Project Appraisal, 18(2), 111-124. 
Leeuwen, E., Vreeker, R., \& Rodenburg, C. (2003). A framework of quality of life assessment of urban green areas in Europe: An application of disrict park Reudnitz Leipzig. Paper Presented at 43rd ERSA Congress. Findland. August, 27-30.

Mihai, A., Marincea, A., \& Ekenberg, L. (2015). A MCDM analysis of the roșia montană gold mining project. Sustainability, 7, 7261-7288.

Nijkamp, P., \& Ouwersloot, H. (1996). A decision support system for regional sustainable development: The Flag Model. Vreij University, Amsterdam.

Nijkamp, P., \& Vreeker, R. (2000). Methods: Sustainability assessment of development scenarios: Methodology and application to Thailand. Ecological Economics, 33, 7-27.

Patterson, A., \& Theobald, K. S. (1995). Sustainable development, agenda 21 and the new local goresnance in Britain. Regional Studies, 29(8), 773-778.

Poveda, C. A., \& Lipsett, M. (2011). A rewiew of sustainability assessment and sustainability/environmental rating systems and credit weighting tools. Journal Sustainable Development, 4(6), 36-52.

Schleicher-Tappeser, R., \& Lukesch, R. (1999). Instrument for sustainable regional development. EURTS Report 9 Freburg. Germany. 